\title{
Digital Taxonomy for Sustainability
}

\author{
Jack H Townsend \\ Web and Internet Science Group, ECS \\ University of Southampton, UK \\ jack@jacktownsend.net
}

\begin{abstract}
Previous strategic analyses of the field of ICT for sustainability (ICT4S) have often underplayed the role of ICTs in linking large numbers of people, in shaping and transferring ideas, and also the range of sustainability effects that ICTs can cause. The Digital Taxonomy for Sustainability (digitaltaxonomy.com) was developed to address this, through a qualitative analysis of over 500 ICT4S company descriptions. It classifies a digital system (software, hardware or social machine) by the digital "means" it employs and the sustainability "ends" it achieves. The possibilities are mapped out with two component taxonomies. The Sustainability Taxonomy identifies around 20 possible sustainability effects of a digital system, such as the sustainable use of natural resources. The Digital Taxonomy identifies over 80 genres of digital system organised onto a matrix. The rows distinguish how the increasing power of digital systems (the digital capabilities) can be applied to the various stages necessary for achieving change, the change processes that form the columns of the matrix. The indirect change processes (assessing, innovating, and adopting) develop and propagate ideas or things to cause the effects, whilst the driving change process acts to cause the effects directly. The digital capabilities are the three ways ICTs can engage with people to drive change: for artificial capability, the ICT provides the action automatically; for augmented capability, the ICT guides them, to inform and influence their behaviour; and for collective capability, the ICT connects them with others, developing networks that link supply and demand. The rapid development and proliferation of ICTs is increasing the power of all three capabilities. This systematic mapping out of the structure of the industry and the field may help stakeholders coordinate, raise external awareness, and inform the development of theory. In particular, it helps identify opportunities for new and better ICT4S systems.
\end{abstract}

Keywords-Web science; human computer interaction; computer science; collective intelligence; smart cities; social machines; ICT for sustainability; cleanweb; sustainable HCI; artificial intelligence; internet science; sustainability science.

\section{INTRODUCTION}

Sustainability challenges such as climate change are among the very greatest of the centuries ahead [1], [2]. There is considerable policy and research interest in building ICT systems to address these challenges, and some companies who create these systems have sold for billions of dollars [3]-[5]. A systematic organisation of both the field and the industry can help groups within them coordinate, raise valuable awareness of them externally [6], and form the basis of new theory. Several industry reports and some researchers have published strategic analyses of ICT for sustainability (ICT4S), notably [7]-[10]. The ICT4S framework by Hilty [8] (Fig. 1) is probably the most authoritative and systematic model of the field. It uses the linked life cycles approach [8] to analyse how ICTs affect the life cycle of other products. It distinguishes between the direct impacts of the ICT hardware itself (firstorder effects), the intentional application of the system (second-order), and the wider systemic effects that are very complex (third-order). It also distinguishes whether each is positive or negative for the environment.

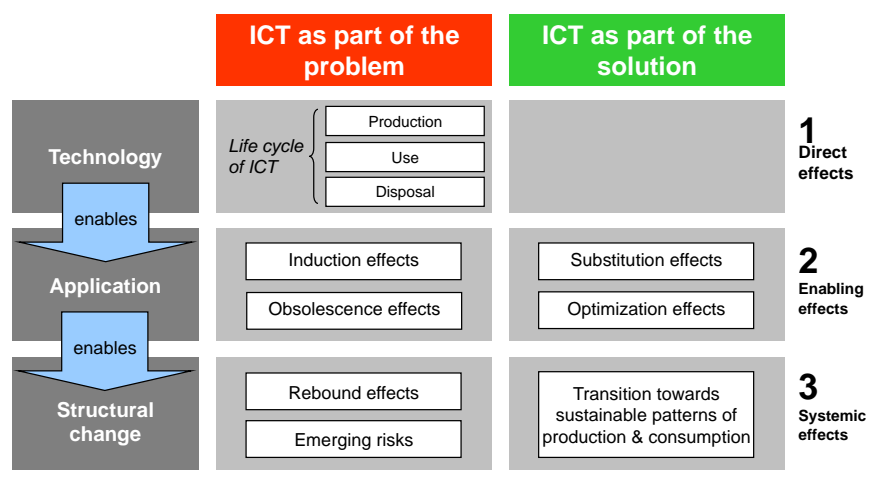

Fig. 1 The Hilty framework of ICT4S [8], showing: the first-order direct effects of ICT hardware; the second-order applications that are the subject of this paper; and third-order systemic effects. (With permission of L. Hilty).

The Web is massive and highly social [5]. It has contrasting characteristics that require interdisciplinary investigation: as a global technical infrastructure; as the largest ever information construct; as new media where we perform socially; and as an industry with its own culture [11], [12]. How can we analyse the role of the Web in sustainability? Where on the Hilty framework should we situate blogs debating climate change ${ }^{1}$, tool-sharing social networks ${ }^{2}$, or crowd identification of photos of rare species $^{3}$ ? There are important features that the framework does not distinguish. First, the role of ICTs in linking large numbers of people to form social machines [13], such as social networks, e-marketplaces, collaborative working, collaborative consumption [14], or crowdfunding. Second, the crucial role of ICTs in shaping and transferring ideas as well as products. Is it possible to consider the life cycle of concepts at the same time as the life cycle of things? New ideas can lead to transformational change, not just optimisation of existing processes. The framework (Fig. 1) identifies such sustainability transition [15] as a systemic effect (third-order), however it can be the intentional application of the system (second-order). Tomlinson analyses such greening through IT, but does not develop a systematic taxonomy [7]. Third, the framework does not specify the nature of the sustainability

1 Real Climate blog http://www.realclimate.org

2 StreetBank http://www.streetbank.com

3 ZSL Instant Wild http://www.edgeofexistence.org/instantwild 
effects. Environmental sustainability presents an array of major challenges leading to contrasting technical and commercial contexts for ICTs, such as the energy, water or conservation sectors (Fig. 2).

To address these challenges, this monograph presents a systematic classification of digital systems for sustainability: the Digital Taxonomy for Sustainability. Mapping out the field and the industry might support their development by helping stakeholders coordinate, raising external awareness, and informing the development of theory. Above all, it helps identify opportunities for new and better ICT4S systems. The Taxonomy's scope is second-order effects, the intentional application of ICTs, but including the role of ideas and of the social. This is version 5.0; an early version was presented at ICT4S2014 [5], and the latest version can be found at digitaltaxonomy.com. It results from my doctoral research and forms a chapter of the thesis [16].

The Taxonomy is made up of two component taxonomies that organise both the digital means and the sustainability ends. The Digital Taxonomy classifies the digital means employed by a digital system (a system based upon ICTs). It is mapped out in Fig. 5, whilst the underlying theory is presented in Section IV and Figs. 3 and 4. All the entries are introduced systematically in Section V, with a number of case studies. On the other hand, the Sustainability Taxonomy classifies the sustainability ends, the environmental impact of the digital system. It is mapped out in Fig. 2 and described in Section III. A particular digital system is classified by identifying both its digital genre and its sustainability effects (terms defined in Sections IV and III respectively).

\section{METHOD}

The primary method was qualitative analysis of over 500 company descriptions. Descriptions were selected that contained both terms relevant to ICT and to sustainability, or terms relevant to ICT4S specifically. The primary sources of this secondary data were the online technology company database CrunchBase and a list by Pascual [17]. Qualitative coding, graphical ideation and taxonomic analysis were then undertaken to develop the taxonomy structure and content iteratively. Identification of sustainability effects (Fig. 2) was also informed by existing taxonomies of traditional industrial sectors [17][20] and of cleantech [21], [22], which are also organised by natural resource used (e.g. energy, water, or food). The empirical and theoretical work was greatly informed by active participation in ICT4S communities, including organising one of the largest regular events on the topic, Cleanweb London ${ }^{4}$. The terminology and iconography were chosen to maximize ease of comprehension. Wikipedia was used to capture up-to-date terminology and definitions of fastevolving digital phenomena that are often lacking in the academic literature. A detailed description of the methods is presented in Chapter 4 the doctoral thesis [16].

\section{SUSTAINABILITY TAXONOMY}

This section describes how digital systems can be organised by their sustainability effects, using the Sustainability

44 Cleanweb UK http://www.cleanweb.org.uk
Taxonomy, which is mapped out in Fig. 2. Along with the Digital Taxonomy (Fig. 5), it makes up the Digital Taxonomy for Sustainability.

To be more environmentally sustainable, humans must mitigate the negative effects they are having upon the Earth System whilst adapting to the changes they are causing [2]. To understand the role of digital systems, we must understand their sustainability effects, the changes that affect the Earth System and the environmental agenda. The Hilty framework captures two key dimensions of this change, whether it is positive or negative for the Earth System, and whether they are first, second or third order. However this does not distinguish between the nature of the sustainability impact: is water saved, is an endangered species conserved, or are children educated about the environment? The Sustainability Taxonomy addresses this by identifying 20 sustainability effects (Fig. 2), identified by the categorisation of 500 ICT4S company descriptions. They are the range of objectives to which digital systems can be applied to advance environmental sustainability (second-order applications in the Hilty framework). The sustainability effects are organised in four groups of increasing complexity, introduced in the sections below: energy use, other resource use, enablers and environmental.

SUSTAINABILITY TAXONOMY

\begin{tabular}{|c|c|c|c|}
\hline \multirow{2}{*}{\multicolumn{2}{|c|}{$\begin{array}{l}\text { SUSTAINABLE RESOURCE USE } \\
\begin{array}{l}\text { Direct resource decoupling } \\
\text { Clean efficiency and productivity }\end{array}\end{array}$}} & \multirow{3}{*}{$\begin{aligned} \text { ENABLERS } & \\
& \text { III.B }\end{aligned}$} & \multirow{3}{*}{$\begin{array}{l}\text { ENVIRONMENTAL } \\
\text { INTERACTIONS } \\
\text { III.C }\end{array}$} \\
\hline & & & \\
\hline ENERGY & $\begin{array}{l}\text { OTHER } \\
\text { RESOURCES }\end{array}$ & & \\
\hline 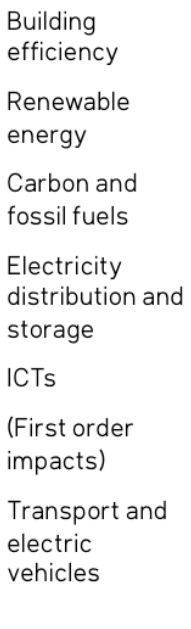 & $\begin{array}{l}\text { Water and } \\
\text { waste water } \\
\text { Food, } \\
\text { agriculture, and } \\
\text { fishing } \\
\text { Waste, } \\
\text { materials and } \\
\text { mineral } \\
\text { extraction } \\
\text { Manufacturing } \\
\text { and supply } \\
\text { chains } \\
\text { Real estate, } \\
\text { storage and } \\
\text { construction } \\
\text { Consumer } \\
\text { goods }\end{array}$ & \begin{tabular}{l} 
Fundamental \\
technology or \\
resource \\
Finance, \\
insurance and \\
resource \\
pricing \\
Sustainability \\
education, arts \\
and media \\
Government, \\
environmental \\
regulation and \\
e-participation \\
\multicolumn{1}{|c|}{ Jack Townsend } \\
digitaltaxonomy.com v5.0
\end{tabular} & $\begin{array}{l}\text { Biodiversity } \\
\text { and habitat } \\
\text { conservation } \\
\text { Adaptation and } \\
\text { resilience to } \\
\text { environmental } \\
\text { risk } \\
\text { Environmental } \\
\text { health and } \\
\text { safety, air } \\
\text { quality } \\
\text { Local economy } \\
\text { and community } \\
\text { General } \\
\text { sustainability }\end{array}$ \\
\hline
\end{tabular}

Fig. 2. The Sustainability Taxonomy organises the sustainability effects of digital systems, identified by classifying the objectives of ICT4S systems. The latest version can be found at digitaltaxonomy.com. Numerals cross-reference to sections of the paper with descriptions.. The social and economic pillars of sustainability are not included.

One digital system may have an array of sustainability effects. For instance, e-Education apps about saving water can achieve behavioural changes (sustainable resource use) at the same time as educating about sustainability (an enabler). 
Sustainability effects themselves have complex interrelationships, with some being precursors of others. In particular, energy, food and water are highly interdependent.

\section{A. Sustainable resource use}

More sustainable use of natural resources requires resource decoupling, i.e. producing and employing resources more efficiently or productively and causing less environmental harm whilst supporting economic activity. This may be the preeminent challenge of environmental sustainability [23], [24]. As saving or generating resources creates income, this area receives much commercial and research attention. In particular, energy use dominates ICT4S, and forms the column at the simplest, most reductionist, end of the Sustainability Taxonomy (Fig. 2). However, there are several other critical natural resources which are listed in the Other Resources column, including water, materials and space. Unfortunately, rebound effects mean that, on their own, efficiency and productivity efforts are likely to be counterproductive overall [23], [25].

This resource use also indicates which industrial sector the digital system operates in. This is because traditional industrial sectors have arisen around the provision of particular resources, such as energy, water or habitable space. This has a number of commercial implications for ICT4S companies, including the nature of the users, customers, competitors, data providers and regulation.

\section{B. Enablers}

Enablers are intermediate steps that support the sustainability objectives of all the other columns of the Sustainability Taxonomy. They include financing, education, regulation and component technologies. Enablers support the adopting process by propagating things and ideas. They therefore align with the digital genres in the adopting columns of the Digital Taxonomy (Fig. 5). These concepts will be introduced in sections IV.A.3 and IV.A.4 below,

\section{Environmental interactions}

At the most complex end of the Sustainability Taxonomy (Fig. 2) lie environmental interactions, a mixed category excluding sustainable resource use, and focused on the interdependent relationship with the Earth System itself, including biodiversity conservation, local environmental quality and health, or adapting to environmental change. These interactions require more holistic perspectives on socially and physically complex challenges than the relative reductionism of sustainable resource use. Sustainability can mean very different things to different groups, and the taxonomy encompasses this diversity. However overall, environmental sustainability can be summarised as addressing these interdependent goals of sustainable resource use and managing our environmental interactions. For simplicity, the social and economic pillars of sustainability are not included.

\section{DigITAL TAXONOMY THEORY}

This section explains the theory behind the Digital Taxonomy, which is mapped out in Fig. 5. It classifies a digital

\footnotetext{
5 Previously termed broad sustainability [5]
}

system by the digital means, the ways it employs digital technology to create change, leading to the sustainability effects (organized in the Sustainability Taxonomy, Fig. 2, Section III).

"The scale of...impact and the rate of ...adoption [of the Web] are unparalleled. [It] is transforming society." [26]. Castells has characterised the change as a new Network Society [6]. But how can we use these digital systems to achieve positive change? "If we are to ensure the Web benefits the human race we must first do our best to understand it." [26]. By classifying the digital systems that make up the Web, and the way they affect change, this Digital Taxonomy can identify opportunities for new and more effective systems. By applying it to the objectives identified in the Sustainability Taxonomy (Fig. 2), these can be better ICT4S systems. Furthermore, having a map of the ICT4S industry and field can help stakeholders coordinate, raise external awareness, and inform the development of theory.

This section classifies digital systems according to their digital genre, a term coined here to mean a category of digital systems that employ ICTs in a similar way. Similar terms include trend, market or vertical. This study identifies three kinds of digital system: hardware, software and social machines. Social machine [13] is a term from web science [27], coined by web pioneer Berners-Lee [28]. Here, it means sociotechnical systems where people are mediated by digital hardware and software. As well as the three kinds of digital system, a digital genre can be a digital institution. Digital institution is coined here to mean practices of digital culture, such as hackathons, entrepreneurship and investor networks.

The digital means is itself organised by means and ends: how the increasing power of digital systems (the digital capability) can be applied to the various stages necessary for achieving change (the change processes, Fig. 3). The Digital Taxonomy (Fig. 5) reflects this by organising the digital genres on a matrix whose rows are the digital capabilities (Fig. 4, Section IV.B), and columns are the change processes (Fig. 3, Section IV.A). The next section $\mathrm{V}$ details the Digital Taxonomy systematics, introducing each cell on this Digital Taxonomy matrix and each of the digital genres it contains, with a number of case studies for illustration.

\section{A. The change processes}

The study identified four change processes (Fig. 3), four steps required to affect change to fulfil objectives (the sought effects). The indirect processes of assessing, innovating, and adopting develop and propagate ideas and things that can then cause the sought effects, whilst the direct process of driving can cause the sought effects directly. All digital genres were found to fit into at least one of the four change processes, which make up the columns of the Digital Taxonomy. There are actually five columns, as it distinguishes between the adopting of things (such as products, technologies, and communities) and the adopting of ideas (the dissemination of knowledge or opinions and the forming of agreements).

The doctoral thesis [14] develops these concepts into a theory of Actor Learning. In it, the four change processes operate together to address complexity through learning. They 
develop and propagate systems that are increasingly effective at addressing particular objectives, such as the those of environmental sustainability

\section{1) Assessing}

The assessing process produces knowledge that can inform action. It works indirectly by generating this actionable knowledge that will increase the effectiveness of action at causing the

. Data and knowledge is gathered, analysed, refined and organised. Patterns are recognised and hypotheses tested. The actionable knowledge generated by the assessing processes informs the decisions of the other change processes, and is often about the challenges being faced and the relative effectiveness of potential action to address those challenges. Assessing is the function of science, business intelligence, knowledge management, medical diagnosis, and legal investigation.

\section{2) Innovating}<smiles></smiles>

The innovating process is where novelty is developed. It works indirectly by designing and prototyping new ideas and new things, or planning alterations to existing ones, in order to have the sought effects. They can then be propagated by the adopting process. Actionable knowledge from the assessing process is employed. Innovating is the function of design, engineering, entrepreneurship, imagination, creativity and brainstorming.

\section{3) Adopting things}

The adopting process is where people propagate things, or take them up. It works indirectly, promoting things that could then have the sought effects, such as buying or selling a product, or joining a group. In adopting things, people decide between options generated in the innovating process, based on knowledge from the assessing process. Adopting things is where designs are realised as functioning products with users, and organisations grow as they recruit new participants. Some examples include: using a website; taking a train; making an investment; joining a political party or a social network. Fields such as marketing, advertising, sales, manufacturing, finance, and security all promote and shape the adopting of things.

\section{4) Adopting ideas (dissemination)}

The adopting process is also where people take up ideas. Such dissemination is the communication, discussion and promotion of facts and opinions, and the negotiation of agreements. This includes knowledge generated by the assessing process, and ideas constructed by the innovating process, which can then inform other people's assessing processes. Dissemination is where people influence and learn from each other, personal and collective beliefs are developed and expressed, and decisions are made on how to proceed. Fields such as the media, politics, campaigning, public relations and education all focus on adopting ideas.

\section{5) Driving}

The driving process generates action. Unlike the three indirect change processes, it causes change directly that can have the sought effects. Before they can function in the driving process, systems must be developed and propagated by the other three indirect change processes.

\section{B. Three digital capabilities}

There are three contrasting ways that the driving process can work: it can provide for, guide or connect people in order to cause the action that has the sought effects. For digital systems, this corresponds to three digital capabilities: artificial, augmented and collective. These concepts were developed and 
defined during the study of ICT4S company descriptions, and are described and compared in Fig. 4.

The term capability is used to mean either intelligence or function. Here, intelligence means the ability to process information to be effective. Digital examples include artificial intelligence agents trading shares; the augmented intelligence of an ecologist using a Geographical Information System; or the collective intelligence of Wikipedia contributors discussing an article. Here, function means the ability to act and cause effects. Digital examples include the artificial function of assembly line robots; the augmented function car satellite navigation systems; or the collective function of rioters coordinating over social networks.

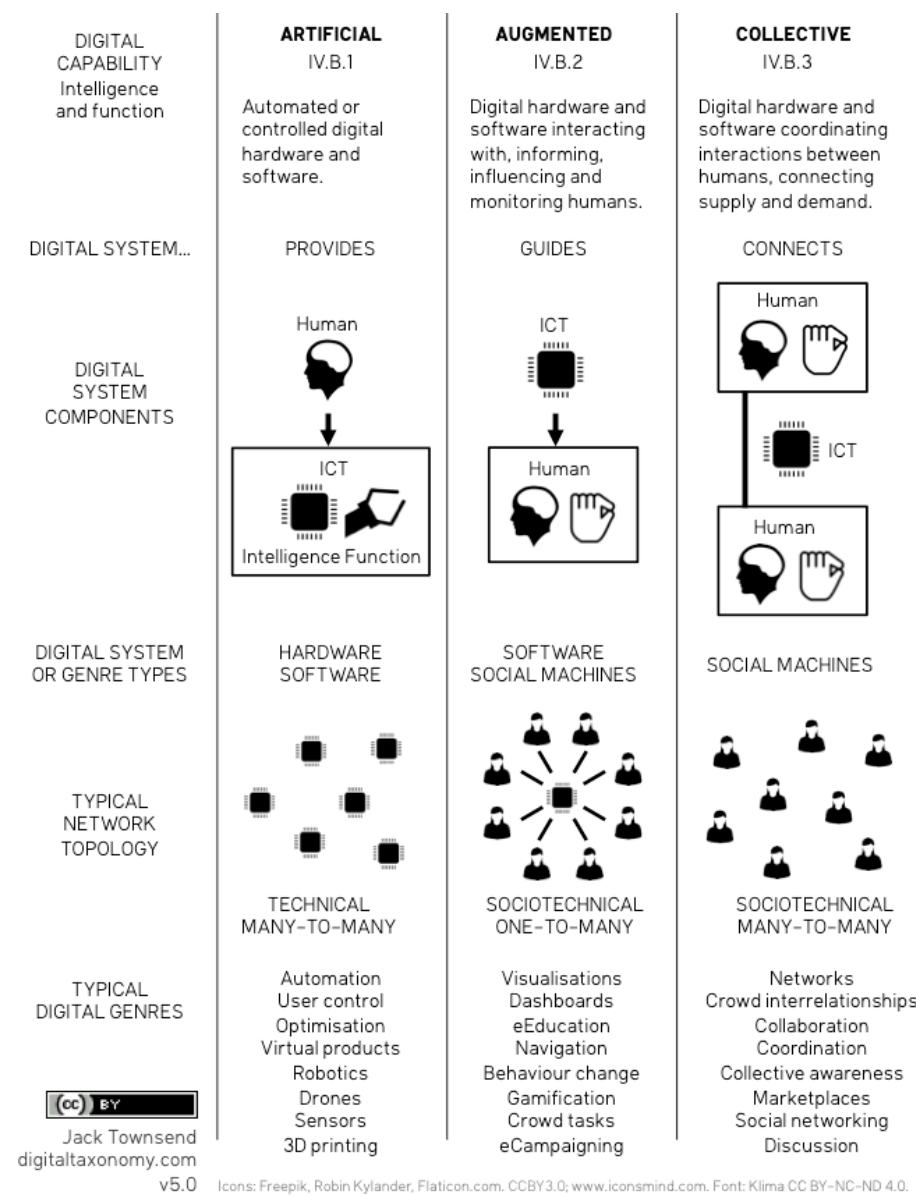

Fig. 4 How digital systems achieve change; comparing the three digital capabilities (intelligence and function) that a digital system can generate to achieve sought effects, depending on how a person is involved. Numerals cross-reference to sections of this paper with descriptions.

The three digital capabilities form the rows of the Digital Taxonomy (Fig. 5). To create change, these capabilities can be applied to each of the four change processes (Fig. 3) that form the columns. The doctoral thesis [16] argues that the power and diversity of all three capabilities is increasing rapidly over time, due primarily to the exponential (or superexponential [29]) growth in the capacities of digital hardware (Moore's Law and similar). The Digital Taxonomy (Fig. 5) identifies the means by which these three increasingly powerful digital capabilities are strengthening all four change processes to increasingly empower people, albeit to greatly different extents [16].

\section{a) Artificial capability}

Artificial capability (artificial intelligence and artificial function) is provided for the person by digital hardware and software. The digital system can reduce the effort required by a person. Someone generally has some level of control, but some digital systems are fully autonomous e.g. viruses.

\section{b) Augmented capability}

Augmented capability (augmented intelligence and augmented function) is generated when the artificial capability of digital hardware and software guide humans by interacting with, monitoring, informing, and influencing them, affecting their behaviour or thinking or both. Augmented capability combines artificial intelligence and function with that of individual humans into networks that tend to have a one-tomany topology, where a digital system broadcasts out information or guides a crowd of individual users largely independently of each other.

Augmented capability depends upon human-computer interfaces, and is the subject of human-computer interaction research. Augmentation systems can: empower the user; act as catalysts that make human behaviours more effective, and regulate them, reinforcing particular outcomes; and create user experiences (UX) offering user journeys, which may eventually alter both behaviour and thinking. As ICTs increasingly structure and record human activity, the information gathered can provide feedback to the user on their behaviour, and highly customised guidance. There has been considerable commercial, research and policy interest in these persuasive technologies [30], gamification [31] and the "libertarian paternalism" of choice architecture and nudging [32].

\section{c) Collective capability}

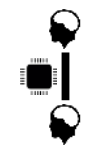

Collective capability (collective intelligence and collective function) is enabled when the artificial capability of digital hardware and software connect people, coordinating interactions between humans and forming networks that link supply and demand for different resources and opportunities. It combines artificial intelligence and function with that of groups of humans. It builds upon the augmented capability by brokering user-to-user relationships. This results in social machines, networks of people and ICTs, often with a distributed many-to-many topology of interacting users. Examples include social networks, online communities, collaboration tools, peer-to-peer file sharing, product service systems, teleconferencing, wikis, ratings and marketplaces. Artificial intelligence is often employed to produce recommender systems that analyse user behaviour and recommend new connections. Collective capability is the most relevant to the Web; the internet allows people to share large amounts of information with great numbers of people at great distances, instantaneously and at near zero cost. Shirky [33] 
explores the implications of such radical lowering of the transaction costs of communication concluding that human actors - often distant strangers - are now able to rapidly selforganise and achieve things without the hierarchical structure of traditional organisations. This high connectivity also enables the long tail [34], a greater diversity of groups developing around rare interests.

\section{Digital TaXonomy Systematics}

The Digital Taxonomy (Fig. 5) organises digital genres on a matrix of digital capabilities (the rows, Fig. 4) and change processes (the columns, Fig. 3). Having described the theory that structures the matrix in the previous section, this section describes each cell of the matrix and briefly introduces the digital genres it contains, with a number of case studies for illustration. A digital system or genre can appear in multiple locations on the taxonomy. The list of digital genres can continue to evolve as new systems are invented, but the matrix should still remain valid.

For the driving process alone, it is necessary to specify its sustainability objectives (sought effects). This is not true for the other change processes as they work indirectly. Because sustainable resource use is the dominant set of sustainability objectives within the ICT4S field and industry (Fig. 2), the next subsection V.A catalogues digital genres that specifically drive this digital efficiency of resource use. However, the Digital Taxonomy table (Fig. 5) is more generic, and uses the term action rather than efficiency for the cells of the driving column. A similar catalogue of digital genres driving environmental interaction objectives (see Fig. 2) is not included.

\section{A. Digital efficiency}

Digital efficiency systems act more efficiently than established alternatives. They apply the driving process to advancing sustainable resource use and thus resource decoupling, the left columns of the Sustainability Taxonomy (Fig. 2). They are more resource efficient, providing more economic and social value for less energy, water, food, materials or other resources expended, and thus less environmental harm.

\section{1) Artificial efficiency}

Artificial efficiency systems automatically operate in more efficient ways. They are hardware or software that harness artificial capability to contribute to resource decoupling with limited human effort. Although just a small part of the whole Digital Taxonomy, it is the primary focus of three dominant areas of green IT: green computing, optimisation, and dematerialisation. The archetypal artificial efficiency system automatically optimises resource-use, such as a domestic heating system, to provide more of the sought effects (a warm home) for less energy expenditure. These systems often simultaneously increase the level of user control over the resource use. A paramount way for digital hardware to increase resource efficiency is through green computing, reducing its first-order effects (Fig. 1) such as its energy and material use, and production of e-waste. New modes of distributed manufacturing such as domestic 3D printing may be more resource efficient than existing centralised production processes, whilst robotics and drones can operate in ways that are more efficient than prior alternatives.

\section{Case study: Nest Learning Thermostat}

The Nest Learning Thermostat ${ }^{6}$ is an artificial efficiency system in the automated optimisation digital genre. It uses automated optimisation based on sensor data to more efficiently heat the home with less cognitive effort for the customer, creating a personalised schedule without the need to programme the device. It also provides greater control of heating to the user with a smartphone app. As a large proportion of all energy use is expended heating and cooling buildings, a smart thermostat can have clear benefits for sustainability.

\section{2) Augmented efficiency}

Augmented efficiency systems guide people to behave in more efficient ways. They are software or social machines that harness augmented capability to inform, monitor and influence people to behave efficiently and contribute to resource decoupling. The archetypal augmented efficiency system is resource use feedback that helps users develop more efficient resource use behaviours. Similarly, leaders of organisations can use business intelligence and process planning software to better manage the resources they control. Persuasive technologies can encourage individual behaviour change, sometimes by getting the user to compete using techniques from video games (gamification), or by guiding the user in real-time, as in navigation systems. Users can find specific advice to behave more efficiently in online knowledge-bases. Alternatively, digital content can be used to dematerialise physical products like books and CD [35].

\section{Case study: Recylebank}

Recyclebank $^{7}$ is an augmented efficiency system in the individual behaviour change and gamification digital genre. It aims to "inspire and reward better everyday choices for a more sustainable future". Over 4.5 million people earn points by participating in household recycling and learning how to live more sustainable lifestyles. Users can redeem rewards in Recyclebank's online shop to choose products that are "better for their home, their wallet and the planet".

\section{3) Collective efficiency}

Collective efficiency systems connect networks of people so they can behave in more efficient ways. They are social machines that harness collective capability, connecting supply and demand to behave efficiently and contribute to resource decoupling. The archetypal collective efficiency system is a product service system that enables people to borrow something for a certain period of time rather than owning it, whilst redistribution markets allow people to exchange things they no longer want, reducing waste and demand for new goods. Connecting people can dematerialise by letting them communicate whilst avoiding travel through teleconferencing and the provision of virtual services. Social approaches to behaviour change and gamification using techniques from video games and user interactions to encourage competition.

6 Nest Learning Thermostat https://store.nest.com/product/thermostat 7 Recyclebank https://www.recyclebank.com/ 
DIGITAL TAXONOMY

\begin{tabular}{|c|c|c|c|c|c|}
\hline \multirow[b]{2}{*}{$\begin{array}{l}\text { DIGITAL } \\
\text { CAPABILITIES } \\
\text { Intelligence and } \\
\text { function }\end{array}$} & \multicolumn{5}{|l|}{ CHANGE PROCESSES } \\
\hline & ASSESSING & INNOVATING & ADOPTING IDEAS & ADOPTING THINGS & DRIVING e.g. EFFICIENCY \\
\hline $\begin{array}{l}\text { ARTIFICIAL } \\
\text { Digital providing }\end{array}$ & $\begin{array}{l}\text { ARTIFICIAL } \\
\text { ASSESSMENT V.E.1 } \\
\text { Sensors } \\
\text { Digital photography } \\
\text { Remote sensing } \\
\text { Simulations } \\
\text { Volunteer computing } \\
\text { Image recognition }\end{array}$ & $\begin{array}{l}\text { ARTIFICIAL } \\
\text { INNOVATION V.D.1 } \\
\text { Computational } \\
\text { creativity } \\
\text { Distributed } \\
\text { manufacturing (rapid } \\
\text { prototyping) }\end{array}$ & $\begin{array}{l}\text { N/A } \\
\text { Guiding } \\
\text { Assessing } \\
\text { Innovating }\end{array}$ & $\begin{array}{l}\text { TECH COMPONENTS V.B.1 } \\
\text { Data processing and storage, } \\
\text { cloud computing } \\
\text { Data transmission and } \\
\text { telecommunications } \\
\text { Enabling robotics, drones } \\
\text { and manufacturing tools } \\
\text { Software languages and } \\
\text { libraries } \\
<\text { Viruses, worms and } \\
\text { botnets> }\end{array}$ & $\begin{array}{l}\text { ARTIFICIAL ACTION V.A.1 } \\
\text { Automated optimization } \\
\text { Robotics and drones } \\
\text { Distributed manufacturing } \\
\text { User control } \\
\text { [First order effects of ICT, } \\
\text { green computing] }\end{array}$ \\
\hline $\begin{array}{l}\text { AUGMENTED } \\
\text { Digital guiding }\end{array}$ & $\begin{array}{l}\text { AUGMENTED } \\
\text { ASSESSMENT V.E.2 } \\
\text { Geographical } \\
\text { information systems } \\
\text { Accounting systems } \\
\text { Crowd sensing } \\
\text { Human computation } \\
\text { Monitoring and } \\
\text { profiling of emotion, } \\
\text { opinion and identity } \\
\text { Data analysis and } \\
\text { mathematical software } \\
\text { Wearable sensors } \\
\text { <Data theft> }\end{array}$ & $\begin{array}{l}\text { AUGMENTED } \\
\text { INNOVATION V.D.2 } \\
\text { Open innovation and } \\
\text { opportunity } \\
\text { identification } \\
\text { Design and } \\
\text { engineering analysis } \\
\text { Knowledge-bases for } \\
\text { design } \\
\text { Ideation catalysts } \\
\text { [Accelerators and } \\
\text { incubators] } \\
\text { [Digital agencies, } \\
\text { software and design } \\
\text { services] }\end{array}$ & $\begin{array}{l}\text { AUGMENTED } \\
\text { DISSEMINATION V.C.1 } \\
\text { News, analysis and } \\
\text { blogs } \\
\text { eEducation and } \\
\text { educational games } \\
\text { Mass e-Campaigning } \\
\text { and public relations } \\
\text { Visualisation and data } \\
\text { journalism } \\
\text { Leaks } \\
\text { Content distribution } \\
\text { Customisation (of ideas) } \\
\text { <Social network bots } \\
\text { and sock puppets> }\end{array}$ & $\begin{array}{l}\text { AUGMENTED ADOPTION V.B.2 } \\
\text { e-Marketing and digital } \\
\text { advertising } \\
\text { Customisation and } \\
\text { installation planning } \\
\text { Customer relationship } \\
\text { management and services } \\
\text { Electronic locks and access } \\
\text { control } \\
\text { Ticketing } \\
\text { File download } \\
\text { <Phishing, trojans and social } \\
\text { engineering> }\end{array}$ & $\begin{array}{l}\text { AUGMENTED ACTION V.A.2 } \\
\text { Behaviour feedback } \\
\text { System diagnostics } \\
\text { Individual behaviour change } \\
\text { and gamification } \\
\text { Business intelligence and } \\
\text { process management } \\
\text { Real-time user guidance and } \\
\text { navigation } \\
\text { Knowledge-bases for action } \\
\text { Crowd tasks } \\
\text { Dematerialised content }\end{array}$ \\
\hline $\begin{array}{l}\text { COLLECT } \\
\text { Digital conn }\end{array}$ & $\begin{array}{l}\text { COLLECTIVE } \\
\text { ASSESSMENT V.E.3 } \\
\text { Wikis and crowd } \\
\text { analytical discussion } \\
\text { Accounting systems } \\
\text { Sensor journalism } \\
\text { Data platforms and } \\
\text { standards } \\
\text { Enterprise } \\
\text { transactions } \\
\text { Ratings and } \\
\text { comparison } \\
\text { (gathering) } \\
\\
\text { Font: Klima CC BY-NC-ND 4.0. Icons: }\end{array}$ & $\begin{array}{l}\text { COLLECTIVE } \\
\text { INNOVATION V.D.3 } \\
\text { Revision control and } \\
\text { collaborative software } \\
\text { Collaborative funding } \\
\text { (for innovation) } \\
\text { Organisational } \\
\text { structuring } \\
\text { Design sharing } \\
\text { [Hackathons, meetups } \\
\text { and coding events] } \\
\text { [lnvestors] } \\
\text { [Digital } \\
\text { entrepreneurship] } \\
\text { reepik, Robin Kylander, Flaticon.com. }\end{array}$ & $\begin{array}{l}\text { COLLECTIVE } \\
\text { DISSEMINATION V.C.2 } \\
\text { Social networking } \\
\text { Agreeing, prioritising, } \\
\text { and e-participation } \\
\text { Forums, comments and } \\
\text { discussion } \\
\text { Peer-to-peer content } \\
\text { sharing } \\
\text { Recommender (ideas) } \\
\text { Activism and protest } \\
\text { coordination } \\
\text { Blogs } \\
\end{array}$ & $\begin{array}{l}\text { COLLECTIVE ADOPTION V.B.3 } \\
\text { Collab. funding (for adoption) } \\
\text { Directories } \\
\text { e-Marketplaces } \\
\text { Job listings } \\
\text { Group purchasing and } \\
\text { community adoption } \\
\text { Offers and discounts } \\
\text { Sales team coordination } \\
\text { Product service systems } \\
\text { Redistribution markets } \\
\text { P2P software sharing } \\
\text { Recommender (things) } \\
\text { Ratings and comparison }\end{array}$ & $\begin{array}{l}\text { COLLECTIVE ACTION V.A.3 } \\
\text { Product service systems } \\
\text { Redistribution markets } \\
\text { Social behaviour change and } \\
\text { gamification } \\
\text { Teleconferencing } \\
\text { Virtual services } \\
\text { Distributed autonomous } \\
\text { corporations (DACs) } \\
\text { Activism, protest coordination, } \\
\text { flash mobs } \\
\text { Distributed crypto-currency } \\
\frac{(\text { (c) EY Jigitaltaxonomy.com v5.0 }}{\text { Jack Townsend }}\end{array}$ \\
\hline
\end{tabular}

Fig. 5 The Digital Taxonomy, a map of genres of digital system identified by classifying the operation of ICT4S systems. They are organised by which digital capability (rows, Fig. 4) they apply to which change process (columns, Fig. 3) in order to create change, such as the sustainability effects of the Sustainablility Taxonomy (Fig. 2). The driving column is about generic action, whilst Section V.A catalogues specific application to resource efficiency. Numerals cross-reference to sections of the paper with descriptions. Square brackets indicate institutions of digital culture, rather than digital systems, and these are classified by driving process type (providing, guiding or connecting) rather than digital capability. Angle brackets indicate malicious approaches e.g. malware. Version 5.0; the latest version can be found at digitaltaxonomy.com.

Future regulation of human behaviour may be automated collectively by distributed autonomous corporations (DACs), a form of algorithmic regulation. Distributed crypto-currencies can be highly inefficient due to the mining of new coins [36], however, others have environmental objectives ${ }^{8}$.

\section{B. Digital adoption}

Digital adoption systems guide people to adopt something that could cause the sought effects. They are catalysts that accelerate the adoption of other things, achieving their ultimate effects indirectly, through the things they propagate. Digital adoption systems for sustainability can employ digital capability to rapidly expand a sustainability project to global scales. They can catalyse the technological substitution for decoupling that Hilty argues is a preeminent challenge of

8 Carbon Coil http://carboncoin.cc/ sustainability [23]. Some digital systems are self-propagating e.g. viruses.

\section{1) Tech components}

Tech components are digital hardware or software that can provide basic components for other systems, manufacture or maintain them. They harness artificial capability to support other systems, technologies and products that can have the sought effects. These include: data processing and storage, cloud computing and software languages and libraries that make ICTs function; the data transmission and telecommunications networking that connect them together; robotics, drones and manufacturing tools that produce and maintain other systems. Malware such as viruses, worms and botnet also automate the process of adoption.

\section{2) Augmented adoption}

Augmented adoption systems guide people to adopt or propagate things. They are software or social machines that 
harness augmented capability to inform, monitor and influence people, to get someone to adopt something. The archetypal augmented adoption systems undertake $e$-marketing and digital advertising to persuade online consumers to buy particular products. Customer relationship management and services tools help organisations manage and support their customer base. With increasing data on user interests, products can be customised to make them more inviting, and software can design and plan the installation. Access to a product can be managed by ticketing and electronic locks and access control, such as mobile apps that can unlock a car door. Users can download software from file distribution sites, whilst phishing, trojans and social engineering install malware.

\section{3) Collective adoption}

Collective adoption systems connect networks of people to adopt or propagate things. They are social machines that harness collective capability, connecting supply and demand to get someone to adopt something. The archetypal collective adoption system is an $e$-marketplace, where buyers and sellers exchange money for products. Collaborative consumption (the sharing economy) offers an efficient alternative: product service systems lend products for a limited period, whilst redistribution markets allow people to exchange things they no longer want. More simply, directories catalogue things so people can find them. People can find investment opportunities, financing or donations through collaborative funding (crowdfunding), or find jobs or employees through job listings systems. Recommender systems can support all these systems by customising to users habits and interests, whilst ratings and comparison better informs choices. Groups can adopt a shared system, or get a better deal with group purchasing and community adoption, or they can find offers and discounts on the things they want. Users can share software peer-to-peer. More indirectly, sales teams can be coordinated to go out and find customers.

\section{Case study: Mosaic}

Mosaic ${ }^{9}$ is a collaborative funding platform, a collective adoption system for renewable energy. Mosaic uses the Web to broker investments between those with sites for potential solar development and those with an interest in funding it, letting individuals invest as little as US\$25 in specific solar projects whilst earning an annual interest.

\section{Digital dissemination}

Digital dissemination systems propagate ideas and support the formation of agreements that motivate the sought effects. As this process must affect humans directly it cannot be undertaken by artificial capability alone, unlike the other change processes.

Digital dissemination systems for sustainability help people communicate and propagate sustainability ideas, competing with other perspectives in politicised and polarised environmental debates about the nature of the challenge and the costs and benefits of potential action. The process is social and often political. The Web acts as O'Neill \& Boykoff's "socially constituted new media", developing from traditional media, in which "struggles of social beliefs and meanings" take place [37].

\section{1) Augmented dissemination}

Augmented dissemination systems guide people to propagate ideas. They are software or social machines that harness augmented capability to inform, monitor and influence people, to get someone to adopt an idea, knowledge or agreement. The archetypal and traditional augmented dissemination systems are news and analysis sites where facts and opinions are broadcast over the Web. Anyone with web access could now achieve the same with a blog. Users can broadcast ideas through content distribution sites such as video sharing, or ebooks libraries. Leaks sites allow individuals to rapidly distribute large quantities of sensitive data. eEducation, data journalism and educational games produce digital experiences to teach about a particular topic. Mass eCampaigning and public relations platforms attempt to persuade large numbers of people to adopt certain beliefs or take particular actions. Visualisation and data journalism analyses and presents proliferating data resources to communicate facts and produce narratives, often interactively, so the user can answer their own questions. Growing quantities of personal data enable automated personalisation of ideas to provide customised content whose message is more likely to be adopted. More surreptitious augmented dissemination uses social network bots to automate the spreading of messages over social networks, whilst human sock puppets take on false personas to advance a particular perspective online.

\section{Case study: Globe-Town}

Globe-Town.org ${ }^{10}$ [38] is an augmented dissemination system in the genres of eEducation and educational games and data visualisation. Globe-Town is a web-based interactive information visualisation using World Bank open data. It builds up a multi-faceted picture of the environmental, economic and social pillars of sustainable development for all the countries of the world. In parallel, it shows that an intensifying network of linkages connect global sustainability issues to the user's home country and the topics that they care about, finding narrative threads of sustainability.

\section{2) Collective dissemination}

Collective dissemination systems connect networks of people to propagate ideas. They are social machines that harness collective capability, connecting supply and demand to get someone to adopt an idea, knowledge or agreement. The archetypal collective dissemination systems are social networks, where people express their opinions and identities, influencing others. Comments and forums enable an increasing tumult of online discussion. Agreeing, prioritising, and $e$ participation systems channel online groups towards agreeing collective decisions on an issue, often as a basis for action. Peer-to-peer content sharing allows users to freely share the ideas within, for instance, ebooks and video. In all these systems, recommender systems can suggest sources of ideas to users by analysing their habits and interests. More indirectly, 
activism and protest coordination systems help groups form around an issue, to organise, campaign and protest.

\section{Digital innovation}

Digital innovation systems design and prototype systems that will have the sought effects. Digital innovation is cocreated between designers and users. Beyond digital systems per se, digital culture is centred on innovation and has developed and proliferated institutions that facilitate it including accelerators, incubators, digital agencies, and hackathons. They are often have a particular theme, and a number are related to sustainability e.g. [10], [39]. Zapico [10], [40], [41] advocates the hands on imperative of the hacker ethic to support sustainability innovation.

\section{1) Artificial innovation}

Artificial innovation systems automatically develop something novel. They are digital hardware or software that harness artificial capability with limited human involvement to design and prototype effective systems. The archetypal genre of artificial innovation system is computational creativity, the use of artificial intelligence to replicate human creativity. Another form is distributed manufacturing and maker culture ${ }^{11}$, as increasingly cheap and powerful 3D printing helps more people undertake rapid prototyping.

\section{2) Augmented innovation}

Augmented innovation systems guide people to develop something novel. They are software or social machines that harness augmented capability to inform, monitor and influence people, to design and prototype effective systems. The archetypal augmented innovation system is sustainable design and engineering analysis (see case study), which guides the designer or engineer through the process of design, providing a virtual environment to work in, and simulating different designs and assessing their potential impacts. Knowledge-bases for design aggregate knowledge on how to design, and ideation catalysts trigger imagination by remixing ideas and generating possibilities. Another important type of guided innovation system are open innovation and opportunity identification systems which recruits large numbers of participants to contribute their creativity to a particular problem. Beyond digital systems per se, digital culture depends upon innovation and has institutions that guide actors to support it: accelerators and incubators train and fund entrepreneurs, whilst digital agencies, software and design services offer digital innovation skills.

\section{Case study: Autodesk Sustainability Workshop}

Autodesk Sustainability Workshop ${ }^{12}$ is an augmented innovation system within the design and engineering analysis, and knowledge-bases for design digital genres. The Autodesk Sustainability Workshop is a free on-line tutorial that covers sustainable design concepts such as light-weighting and whole systems thinking. These videos instruct viewers how to make sustainable design decisions early in the design process. Their "solutions for Digital Prototyping allow designers,

\footnotetext{
11 E.g. Fab conferences www.fab10.org

12 http://sustainabilityworkshop.autodesk.com
}

manufacturers and engineers to design more sustainably by reducing the amount of physical prototypes required for a project, or eliminating the need for them entirely."

\section{3) Collective innovation}

Collective innovation systems connect networks of people to develop something novel. They are social machines that harness collective capability, connecting supply and demand to design and prototype effective systems. The archetypal collective innovation system is revision control and collaborative software, which coordinates many people working collaboratively on the same project. Design sharing sites allow people to share or sell designs to others, such as design files for 3D printing. Collaborative funding systems help people find investment opportunities, financing or donations for their innovative projects. Software can also support the planning of organisational structures so people can work together more effectively. Beyond digital systems per se, digital culture itself depends upon innovation and has developed institutions that connect human actors to support it: networks of entrepreneurs and investors finance innovation, whilst hackathons, meetups and coding events bring teams together to develop new ideas.

\section{E. Digital assessment}

Digital assessing systems generate knowledge to make action more effective at creating the sought effects. Many gather data from sensors, or use humans to crowd sense the state of the environment, or the functioning of other systems. Others share, analyse and store data and knowledge. Digital assessing systems for sustainability often monitor the state of the environment, and analyse the potential impact of sustainability challenges or the relative effectiveness of potential action.

\section{1) Artificial assessment}

Artificial assessment systems automatically generate knowledge. They are digital hardware or software that, with limited human effort, gather, discover, analyse and refine actionable knowledge to make action more effective. The archetypal genre of artificial assessing system is the digital sensor, a transducer that detects some characteristic of its environment. Sensors come in myriad forms from medical CAT scanners to the Hubble telescope. Digital photography is an important example, as is satellite-based remote sensing of the Earth's surface. Simulations of the real world allow predictions and forecasts to be made. The great computing power for such simulations can be accrued from many individuals' devices through volunteer computing.

\section{2) Augmented assessment}

Augmented assessment systems are software or social machines that automatically generate knowledge. They harness augmented capability to inform, monitor, and influence people to gather, discover, analyse and refine knowledge to make action more effective. The archetypal augmented assessment system is a crowd sensing system such as citizen science projects, where people are guided to gather environmental data. Similarly in human computation systems they are guided to analyse information. Software packages such as geographical information systems and data analysis, statistics and 
mathematical software provide environments in which people can analyse and visualise data. Accounting systems do both to monitor an organisation's operations. Monitoring users themselves is rich source of information from social network opinion and emotion monitoring enabling the profiling of opinion and identity.

\section{Case study: credit360 Energy and Carbon}

credit360 Energy \& Carbon ${ }^{13}$ is an augmented assessing system in the accounting digital genre. It is a sustainability and carbon accounting tool that gathers real-time and data from across an organisation in order to calculate greenhouse gas emissions. It then creates performance reports and dashboards. Forecasting and planning tools manage energy reduction initiatives and visualise the impact of different scenarios on long-term performance.

\section{3) Collective assessment}

Collective assessment systems connect networks of people to generate knowledge. They are social machines that harness collective capability, connecting supply and demand to gather, discover, analyse and refine knowledge to make action more effective. The archetypal collective assessment system is crowd analytical discussion that takes place in wikis and the forums of citizen science projects, allowing people to gather and organise knowledge together, and to discuss and agree which knowledge is valid. Another form of collective assessing is data platforms and standards that allow information to be found and shared effectively between different people and with machines. In ratings and comparison systems, people can rate products or each other to assess quality using the wisdom of the crowds [42]. Organisations use enterprise transaction systems to monitor and manage the interactions between different employees, departments, customers and suppliers. Sensor journalism creates and shares narratives directly from sensor data. An illegitimate means of gathering information is data theft by circumventing computer security.

\section{CONCLUSION}

This monograph presents a systematic classification of digital systems for sustainability: the Digital Taxonomy for Sustainability (digitaltaxonomy.com). It goes beyond previous work to systematise the role of ideas and of the social. It is composed of the Digital Taxonomy (Fig. 5) that classifies digital systems by the way they employ the increasing power of digital technologies to achieve change (the means), and the Sustainability Taxonomy (Fig. 2) that classifies them by the sustainability effects (the ends). This systematic mapping out of the industry and the field may help stakeholders coordinate, raise external awareness, and inform the development of theory. In particular, it helps identify opportunities for new and better ICT4S systems.

\section{ACKNOWLEDGEMENTS}

I would like to thank Sunny Townsend, Andrea Prieto, Alex Rogers, Sonny Masero, Oriol Pascual, Chris Adams, Jorge Zapico, Sameer Rashid, Woon Tan, Jason Noble and Gail Taylor for useful comments and discussions.

\section{VIII.REFERENCES}

[1] G. Brundtland, "Our common future," Oxford Pap., 1987.

[2] Intergovernmental Panel on Climate Change (IPCC), "IPCC Fourth Assessment Report (AR4)," 2007.

[3] S. Masero and J. H. Townsend, "Cleanweb in the UK: How British Companies are using the Web for Economic Growth \& Environmental Impact (Nesta)," 2014.

[4] A. Chopra and N. Sinai, "Building a Strong, Lasting Economy With Energy Innovation," The White House, Office of Science and Technology Policy, 2012. [Online]. Available: http://www.whitehouse.gov/blog/2012/01/26/building-stronglasting-economy-energy-innovation. [Accessed: 26-Feb-2014].

[5] J. H. Townsend, "Web for Sustainability: Tackling Environmental Complexity with Scale," in ICT for Sustainability 2014, 2014.

[6] D. Hicks, "Structural change and industrial classification," Struct. Chang. Econ. Dyn., vol. 22, no. 2, pp. 93-105, Jun. 2011.

[7] B. Tomlinson, Greening Through IT: Information Technology for Environmental Sustainability, vol. 28, no. 6. 2010.

[8] L. M. Hilty, Information Technology and Sustainability: Essays on the Relationship between Information Technology and Sustainable Development. Books on Demand, 2008.

[9] B. Knowles, "Cyber-Sustainability: Towards a Sustainable Digital Future," Lancaster University, 2014.

[10] J. L. Zapico, "Hacking for Sustainability," KTH, Sweden, 2013.

[11] S. Halford, C. Pope, and L. Carr, "A manifesto for web science?," pp. 1-6, 2010.

[12] M. Castells, The Internet Galaxy: Reflections on the Internet, Business, and Society. Oxford University Press, 2001.

[13] N. Shadbolt, D. Smith, E. Simperl, M. Van Kleek, Y. Yang, and W. Hall, "Towards a classification framework for social machines," SOCM2013 Theory Pract. Soc. Mach., 2013.

[14] R. Botsman and R. Rogers, "What's mine is yours: The rise of collaborative consumption," 2010.

[15] R. Kemp, D. Loorbach, and J. Rotmans, "Transition management as a model for managing processes of co-evolution towards sustainable development," Int. J. Sustain. Dev. World Ecol., vol. 14, no. 1, pp. 78-91, Feb. 2007.

[16] J. H. Townsend, "Doctoral thesis, pending," 2015.

[17] O. Pascual, "Cleanweb: Opportunities in the Intersection of the Internet and Sustainability."

[18] B. Mirel, Interaction Design for Complex Problem Solving: Developing Useful and Usable Software. Morgan Kaufmann, 2004

[19] E. L. Prosser, UK Standard Industrial Classification of Economic Activities 2007 ( SIC 2007 ) Structure and explanatory notes, vol. 2007, no. Sic. 2007.

[20] "Pure Energy Partners." [Online]. Available: http://pureenergypartners.com/. [Accessed: 16-Aug-2014].

[21] Kachan \& Co., "Two years later: Revisiting the taxonomy of cleantech," 2012. [Online]. Available:

http://www.kachan.com/content/two-years-later-revisitingtaxonomy-cleantech. [Accessed: 16-Aug-2014].

[22] Cleantech Group, "Cleantech i3 - Insight and Data Across the Global Clean Technology Marketplace," 2013. [Online]. Available: http://research.cleantech.com/front_page?ref=/tags/.

[23] L. M. Hilty, W. Lohmann, and E. Huang, "Sustainability and ICT An overview of the field," pp. 13-28, 2011.

[24] W. Crane, F. Krausmann, N. Eisenmenger, S. Giljum, P. Hennicke, R. Kemp, P. R. Lankao, B. S. Manalang, and S. Sewerin, Decoupling Natural Resource Use and Environmental Impacts from Economic Growth - UNEP.

[25] M. Berners-Lee and D. Clark, The Burning Question: We can't burn half the world's oil, coal and gas. So how do we quit? Profile Books, 2013.

[26] Web Science Trust, "What is Web Science?," 2010. [Online]. Available: http://webscience.org/webscience.html. [Accessed: 22Aug-2011].

[27] T. Berners-Lee, D. J. Weitzner, W. Hall, K. O’Hara, N. Shadbolt, and J. A. Hendler, “A Framework for Web Science,” Found. Trends Web Sci., vol. 1, no. 1, pp. 1-130, 2006. 
[28] T. Berners-Lee and M. Fischetti, Weaving the Web: The original design and ultimate destiny of the World Wide Web by its inventor. Orion Business, 1999.

[29] B. Nagy, J. D. Farmer, J. E. Trancik, and J. P. Gonzales,

"Superexponential long-term trends in information technology," Technol. Forecast. Soc. Change, vol. 78, no. 8, pp. 1356-1364, Oct. 2011.

[30] B. Fogg, "Persuasive technology: using computers to change what we think and do," Ubiquity, 2002.

[31] L. Von Ahn, "Games with a purpose," Computer (Long. Beach. Calif)., 2006

[32] R. H. Thaler and C. R. Sunstein, Nudge: Improving Decisions About Health, Wealth, and Happiness. Penguin (Non-Classics), 2009.

[33] C. Shirky, Here Comes Everybody: The Power of Organizing Without Organizations. Penguin (Non-Classics), 2009.

[34] C. Anderson, The Long Tail: Why the Future of Business is Selling Less of More. Hyperion, 2006.

[35] N. Negroponte, Being Digital. Vintage, 1996.
[36] M. Gimein, "Virtual Bitcoin Mining Is a Real-World Environmental Disaster," Bloomberg Business, 2013. [Online]. Available: http://www.bloomberg.com/news/articles/2013-04-12/virtualbitcoin-mining-is-a-real-world-environmental-disaster. [Accessed: 22-Jun-2015].

[37] S. O’Neill and M. Boykoff, “The Role of New Media In Engaging the Public With Climate Change," in Growth (Lakeland), 2009.

[38] J. H. Townsend, R. Gomer, W. Fyson, D. Hobson, H. Fryer, A Prieto, G. Taylor, and N. Shadbolt, "Creating an Open Data Application for Sustainability Education: Globe-Town," in Proceedings of the LinkedUp Veni Open Education Competition 2013.

[39] “The Cleanweb Initiative.” [Online]. Available: http://cleanweb.co/. [Accessed: 08-Mar-2014]

[40] J. L. Zapico, "The Hacker Ethic, Openness, and Sustainability," in The Open Book, Open Knowledge Foundation, 2012.

[41] P. Himanen, The hacker ethic: A radical approach to the philosophy of business. Random House, 2002

[42] J. Surowiecki, The Wisdom of Crowds. Anchor, 2005. 